\title{
Association Study of the TREM2 Gene and Identification of a Novel Variant in Exon 2 in Iranian Patients with Late-Onset Alzheimer's Disease
}

\author{
Zohreh Mehrjoo ${ }^{a}$ Amin Najmabadic Seyedeh Sedigheh Abedini ${ }^{a}$ \\ Marzieh Mohseni $^{a}$ Koorosh Kamalib Hossein Najmabadia \\ Hamid Reza Khorram Khorshid ${ }^{a}$ \\ ${ }^{a}$ Genetics Research Center, University of Social Welfare and Rehabilitation Sciences, and ${ }^{\mathrm{b}}$ Reproductive \\ Biotechnology Research Center, Avicenna Research Institute, Academic Center for Education Culture and Research, \\ Tehran, Iran; ' Division of Biological Sciences, University of California, San Diego, Calif., USA
}

\section{Key Words}

Alzheimer's disease $\cdot$ TREM2 Iranian population

\begin{abstract}
Objective: To analyze the association between TREM2 exon 2 variants and late-onset (sporadic) Alzheimer's disease (AD) in an elderly Iranian population. Materials and Methods: Exon 2 of TREM2 in a total of 131 AD patients and 157 controls was genotyped using polymerase chain reaction and Sanger sequencing. Fisher's exact test was used to compare the allele and genotype frequency between the 2 study groups. Results: One homozygous and 2 heterozygous carriers of rs 75932628-T in the AD patients and 1 heterozygous carrier in the control group were identified. One novel damaging variant, G55R, was also detected in the $A D$ patient group. The frequency of rs75932628-T as well as the amount of rare variants were higher in the AD patients than in the controls, but this did not reach a statistically significant association with $A D$ (odds ratio: $4.8 ; 95 \%$ confidence interval: 0.54 to $43.6 ; p=0.270$ ). Conclusion: The rs75932628-T allele frequency in the elderly Iranian population $(0.86 \%)$ was high.
\end{abstract}

(c) 2015 S. Karger AG, Basel

\begin{tabular}{ll}
\hline KARGER 125/\% & $\begin{array}{l}\text { (1) 2015 S. Karger AG, Basel } \\
\text { 1011-7571/15/0244-0351\$39.50/0 Open car }\end{array}$ \\
$\begin{array}{l}\text { E-Mail karger@karger.com } \\
\text { www.karger.com/mpp }\end{array}$ & $\begin{array}{l}\text { This is an Open Access article licensed under the terms of the } \\
\text { Creative Commons Attribution-NonCommercial 3.0 Un- } \\
\text { ported license (CC BY-NC) (www.karger.com/OA-license), } \\
\text { applicable to the online version of the article only. Distribu- } \\
\text { tion permitted for non-commercial purposes only. }\end{array}$
\end{tabular}

\section{Introduction}

Dementia, a major disability in elderly people, is increasing in developing countries as a result of the demographic trend toward older age groups [1-3]. The most common form of dementia is Alzheimer's disease (AD) which is defined as a neurodegenerative disorder that affects memory, behavior, and thinking ability, and then impairs basic body movement, eventually leading to death [4]. AD usually begins to manifest around the age of 65 and affects half of the population aged $\geq 85$ years in its late-onset form [5]. Aside from aging, family history and genetics also influence $\operatorname{AD}[4,5]$.

A number of studies have been performed on the genetic causes and risk factors of AD. Mutations in $A \beta P P$, PSEN1 and PSEN2 cause familial early-onset AD that typically begins before age 65 [2]. One of the most significant late-onset (sporadic) $\mathrm{AD}$ risk factors is allele $\varepsilon 4$ of the $A p o$ $E$ gene. Based on the estimations, $40-65 \%$ of AD patients possess 1 or 2 copies of the Apo E E4 gene [4]. Recent studies disclosed another significant $\mathrm{AD}$ risk factor, the rs75932628-T allele, with a significance similar to Apo E $\varepsilon 4$ 's $[6,7]$. This allele is a rare nonsynonymous variant in

Dr. Hamid Reza Khorram Khorshid, MD, PhD

Genetics Research Center

University of Social Welfare and Rehabilitation Sciences

Koodakyar Avenue, Evin, Tehran 1985713834 (Iran)

E-Mail hrkk1@uswr.ac.ir 
Table 1. Comparison of sex, educational stages, ethnicity, occupation, and mean age between AD patients and controls

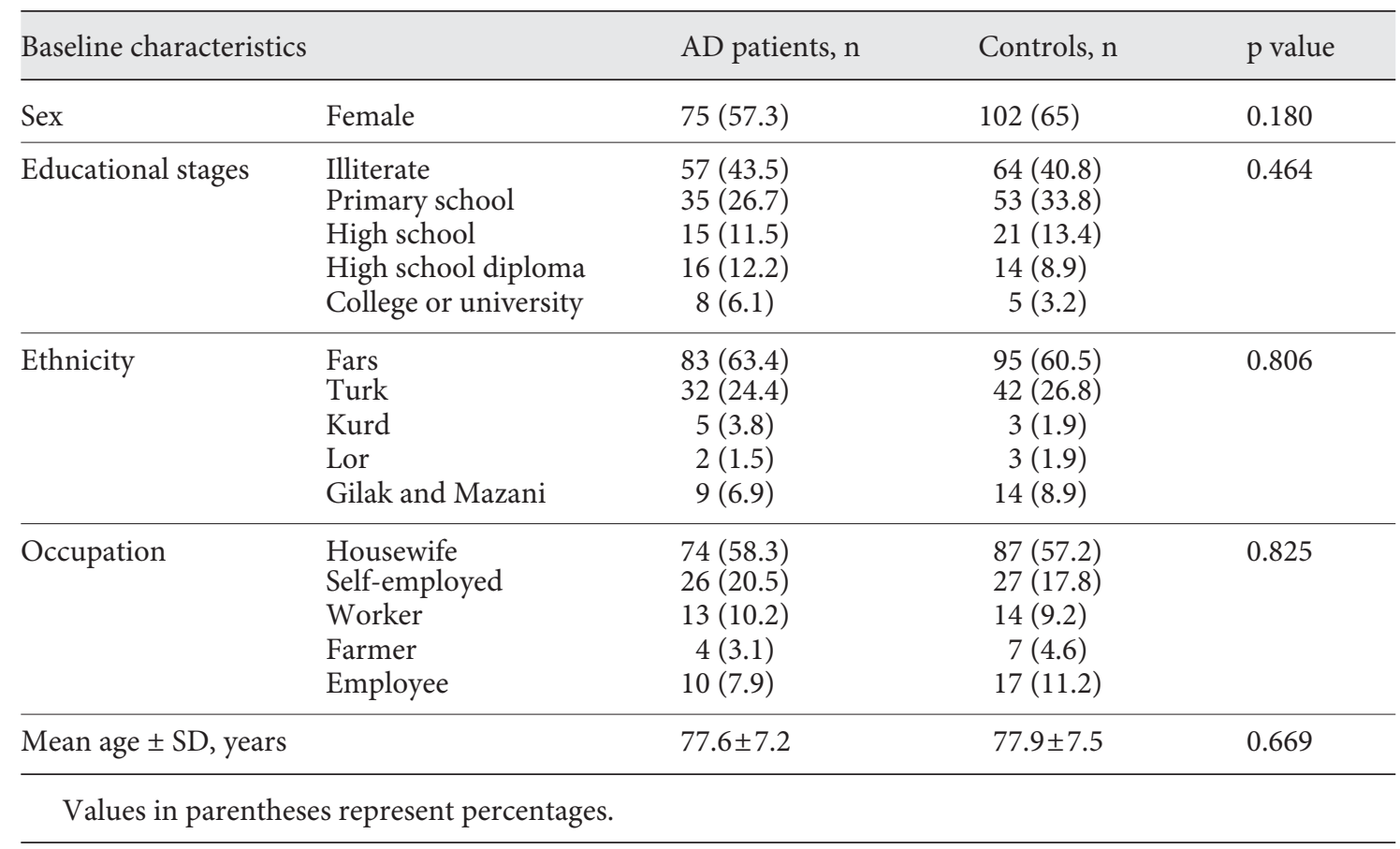

exon 2 of triggering receptor expressed on the myeloid cells 2 gene (TREM2, OMIM 605086). This variant is predicted to cause $\mathrm{R} 47 \mathrm{H}$ in the TREM2 IgV domain. Aside from rs75932628- $T$, the abundance of other variants in exon 2 of the TREM2 gene in $\mathrm{AD}$ patients versus the comparative lack of variants in healthy individuals was also reported to be significant [6]. The TREM2 protein takes part in innate immunity by its expression as a receptor on the surface of microglia, macrophages, osteoclasts, and monocyte-derived dendritic cells [8]. In the brain, the TREM2 protein participates in the phagocytosis of cell debris and apoptotic materials during anti-inflammatory processes [9]. Mutations in TREM2 have been reported in other diseases with early-onset dementia, for example in polycystic lipomembranous osteodysplasia with sclerosing leukoencephalopathy, frontotemporal dementia-like syndrome, and frontotemporal lobar degeneration [1012].

So far, the association of TREM2 variants with AD has not been studied in the Iranian population. Hence, we performed this study to determine the abundance of rare variants in exon 2 of the TREM2 gene, including rs75932628-T, in AD patients and controls from 6 different ethnicities living in the Middle Eastern country Iran: Fars, Turk, Kurd, Lor, Gilak, and Mazani.

\section{Subjects and Methods}

\section{Subjects}

Blood samples from 131 late-onset (sporadic) AD patients (75 female and 56 male) were collected from Iran's Alzheimer's Association as well as from the Kahrizak, Mehrvarzan, and Farzanegan nursing homes from autumn of 2007 until summer 2008. The patients were diagnosed with $\mathrm{AD}$ by physicians according to the $\mathrm{Di}$ agnostic and Statistical Manual of Mental Disorders, fourth edition (DSM-IV) criteria. The inclusion criteria were: age $\geq 65$ years, absence of a familial history of $\mathrm{AD}$, and having no other neurologic or psychiatric diseases. Blood samples from 157 controls (102 female, 55 male) were collected from the same nursing homes and the laboratory of the Rheumatology Center of Iran. The patients and controls were adjusted for age, sex, ethnicity, educational stages, and occupation.

This study was approved by the Ethics Committee of Iran's Ministry of Health and Medical Education, and written informed consent was obtained from all of the patients and controls.

\section{Molecular Genetic and Statistical Analysis}

The DNA was extracted from the blood samples using the salting out method [13]. To genotype exon 2 of the TREM2 gene in patients and controls, primers were designed for this region using the Primer3Plus software [14]. The DNA samples were amplified by polymerase chain reaction, followed by Sanger sequencing. Then, the samples were analyzed with the CodonCode aligner software, version 4.0.4 (CodonCode Corp., Dedham, Mass., USA). The phenotypic effects of observed variants were predicted using the Polyphen2 software [15]. 
Table 2. Variants found in exon 2 of TREM2 through Sanger sequencing in 131 AD patients and 157 controls

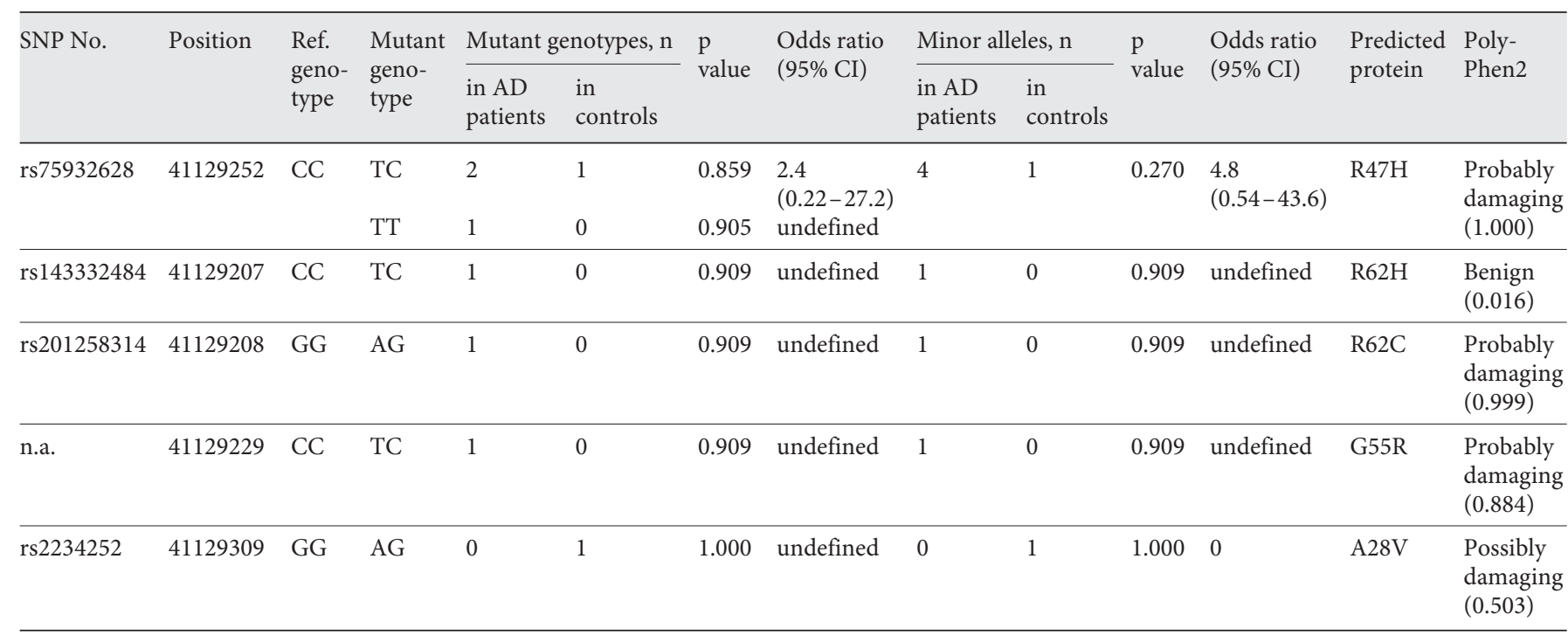

$\mathrm{CI}=$ Confidence interval; $\mathrm{n} \cdot \mathrm{a}=$ not available; $\mathrm{SNP}=$ single nucleotide polymorphism.

The statistical analyses were conducted with SPSS 11.5 (SPSS Inc., Chicago, Ill., USA). Fisher's exact test was used for the comparison of the allele and genotype frequencies between the 2 study groups. The $\chi^{2}$ test was used to compare the potential confounding variables age, sex, ethnicity, educational stages, and occupation between the patients and controls. Four patients and 5 controls were excluded from the analysis because their occupational data were not available. $p$ values $<0.05$ were assumed to be statistically significant.

\section{Results}

No significant differences were observed between the cases and controls in age, sex, ethnicity, educational stages, and occupation using the $\chi^{2}$ test $(\mathrm{p}>0.05$; table $1)$. One homozygous and 2 heterozygous carriers of rs75932628- $\mathrm{T}$ in AD patients and 1 heterozygous carrier in the control group were identified (table 2). This rare variant was identified in $2.29 \%$ of cases and $0.63 \%$ of controls, but it did not reach a statistically significant association with $\mathrm{AD}$ (odds ratio: $4.8 ; 95 \%$ confidence interval: 0.54 to $43.6 ; \mathrm{p}=0.270$; table 2 ). Three more variants ( $\mathrm{p}$. R62H, p.R62C, and p.G55R) and 1 variant (p.A28V) were detected in $\mathrm{AD}$ patients and controls, respectively. The p.G55R with the 'probably damaging' predicted phenotype has not been reported before (table 2). The abundance of rare variants was higher in the $\mathrm{AD}$ patients than in the controls, but this did not show a statistically significant association with $\mathrm{AD}$ (odds ratio: 4.8 ; $95 \%$ confidence interval: 0.54 to $43.6 ; \mathrm{p}=0.270$; table 2).

Association Study and Finding of a Novel Variant in the TREM2 Gene

\section{Discussion}

Although more variants were observed in the $\mathrm{AD}$ patient population compared to the control group, neither the abundance of TREM2 rare variants nor the rs75932628-T variant showed a statistically significant association with $\mathrm{AD}$. In our study, the $0.86 \%$ frequency of the rs75932628-T allele in the Iranian population was higher than the reported frequencies of this allele in other studied populations, which were $0.65 \%$ in Icelandicorigin [7], 0.3\% in Spanish-origin [16], and 0.29\% in European- or American-origin populations [17].

Previously, Jonsson et al. [7] and Guerreiro et al. [6] studied thousands of samples with European or North American descent and showed that rs75932628- $\mathrm{T}$ is a significant risk factor for $\mathrm{AD}$ in these populations. These findings were confirmed by other studies in Spanish, French, and American Caucasians [16-18]. In studies which showed that the rs-75932628-T variant was significantly associated with $\mathrm{AD}$, the amounts of samples were higher than in our study, ranging from 3.65 to 28 times $[6,16]$. Therefore, considering the higher rate of rs75932628-T allele frequency in Iranian samples than that in previous studies, and also the higher prevalence of rs75932628-T allele in our AD patients than in the controls, increasing the sample size probably will reveal a significant result of association between the rs75932628-T allele and AD in the Iranian population. 
Replicating studies in Asian populations did not support a statistically significant association of TREM2 variants with $\mathrm{AD}$ [19-22]. Yu et al. [19] observed no rs75932628-T variants in thousands of AD patients and controls from a northern Han Chinese population. In the Japanese population, 1 out of 2,190 AD patients and 2 out of 2,498 controls were heterozygous carriers of rs75932628-T [21]. Accordingly, the rs75932628-T seems to be very rare in Eastern Asian population. Our results show that the Iranian population is more similar to the European than to the Eastern Asian population concerning the $\mathrm{AD}$ risk factor rs75932628-T allele. The limitation of this study is its small sample size which could account for the lack of statistical significance.

\section{Conclusion}

A high frequency $(0.86 \%)$ of the rs-75932628-T allele was observed in Iranian-origin samples, but our results did not show a statistically significant difference between the $\mathrm{AD}$ patients and the controls.

\section{Acknowledgments}

We would like to thank all of the patients with $\mathrm{AD}$ and their family members who participated in this study.

\section{Disclosure Statement}

The authors have no conflicts of interest to declare.

\section{References}

1 Pang W, Li Z, Sun Z, et al: Prevalence of hypertension and associated factors among older rural adults: results from Liaoning Province, China. Med Princ Pract 2010;19:22-27.

2 Alzheimer's Disease International: World Alzheimer Report 2009. http://www.alz.co.uk/research/files/WorldAlzheimerReport.pdf.

-3 Kalaria RN, Maestre GE, Arizaga R, et al: Alzheimer's disease and vascular dementia in developing countries: prevalence, management, and risk factors. Lancet Neurol 2008;7:812826.

44 Alzheimer's Association: 2013 Alzheimer's disease facts and figures. Alzheimers Dement 2013;9:208-245.

5 Castellani RJ, Rolston RK, Smith MA: Alzheimer disease. Dis Mon 2010;56:484-546.

6 Guerreiro R, Wojtas A, Bras J, et al: TREM2 variants in Alzheimer's disease. N Engl J Med 2013;368:117-127.

7 Jonsson T, Stefansson H, Steinberg S, et al: Variant of TREM2 associated with the risk of Alzheimer's disease. N Engl J Med 2013;368: 107-116.

8 Colonna M: TREMs in the immune system and beyond. Nat Rev Immunol 2003;3:445453

9 Rohn TT: The triggering receptor expressed on myeloid cells 2: 'TREM-ming' the inflammatory component associated with Alzheimer's disease. Oxid Med Cell Longev 2013; 2013:86095
10 Giraldo M, Lopera F, Siniard AL, et al: Variants in triggering receptor expressed on myeloid cells 2 are associated with both behavioral variant frontotemporal lobar degeneration and Alzheimer's disease. Neurobiol Aging 2013;34:2077.e11-e18.

11 Guerreiro RJ, Lohmann E, Brás JM, et al: Using exome sequencing to reveal mutations in TREM2 presenting as a frontotemporal dementia-like syndrome without bone involvement. JAMA Neurol 2013;70:78-84.

12 Paloneva J, Mandelin J, Kiialainen A, et al: DAP12/TREM2 deficiency results in impaired osteoclast differentiation and osteoporotic features. J Exp Med 2003;198:669-675.

13 Miller SA, Dykes DD, Polesky HF: A simple salting out procedure for extracting DNA from human nucleated cells. Nucleic Acids Res 1988;16:1215.

14 Untergasser A, Nijveen H, Rao X, et al: Primer3Plus, an enhanced web interface to Primer3. Nucleic Acids Res 2007;35(Web Server issue): W71-W74.

15 Adzhubei IA, Schmidt S, Peshkin L, et al: A method and server for predicting damaging missense mutations. Nat Methods 2010;7: 248-249.
16 Benitez BA, Cooper B, Pastor P, et al: TREM2 is associated with the risk of Alzheimer's disease in Spanish population. Neurobiol Aging 2013;34:1711.e15-e17.

-17 Gonzalez Murcia JD, Schmutz C, Munger C et al: Assessment of TREM2 rs75932628 association with Alzheimer's disease in a population-based sample: the Cache County Study. Neurobiol Aging 2013;34:2889.e11-e313.

18 Pottier C, Wallon D, Rousseau S, et al: TREM2 $\mathrm{R} 47 \mathrm{H}$ variant as a risk factor for early onset Alzheimer's Disease. J Alzheimers Dis 2013; 35:45-49.

19 Yu JT, Jiang T, Wang YL, et al: Triggering receptor expressed on myeloid cells 2 variant is rare in late-onset Alzheimer's disease in Han Chinese individuals. Neurobiol Aging 2014; 35:937.e1-e3

20 Ma J, Zhou Y, Xu J, et al: Association study of TREM2 polymorphism rs75932628 with lateonset Alzheimer's disease in Chinese Han population. Neurol Res 2014;36:894-896.

21 Miyashita A, Wen Y, Kitamura N, et al: Lack of genetic association between TREM2 and late-onset Alzheimer's disease in a Japanese population. J Alzheimers Dis 2014;41:10311038.

22 Jiao B, Liu X, Tang B, et al: Investigation of TREM2, PLD3, and UNC5C variants in patients with Alzheimer's disease from mainland China. Neurobiol Aging 2014;35:2422. e9-e11. 